\title{
Validity of the European short list of respiratory diseases: a 40-year autopsy study
}

\author{
Anne K. Gulsvik ${ }^{1}$, Andreas H. Henriksen ${ }^{2}$, Einar Svendsen ${ }^{3}$, Sjur Humerfelt ${ }^{4}$ and \\ Amund Gulsvik ${ }^{2}$ \\ Affiliations: \\ ${ }^{1}$ Medical Dept, Diakonhjemmet Hospital, Oslo, Norway. \\ ${ }^{2}$ Section of Thoracic Medicine, Dept of Clinical Science, University of Bergen, Bergen, Norway. \\ ${ }^{3}$ Dept of Pathology, The Gade Institute, Haukeland University Hospital, University of Bergen, Bergen, Norway. \\ ${ }^{4}$ Clinic of Allergology and Respiratory Medicine, Oslo, Norway.
}

\section{Correspondence:}

Amund Gulsvik, Haakon den Godes vei 10C, 0373 Oslo, Norway. E-mail: amund.gulsvikamed.uib.no

ABSTRACT The predictors of autopsy and the accuracy of European short list (E) codes of respiratory diseases lack recent knowledge.

A $10 \%$ random sample $(n=6811)$ of inhabitants of Bergen, Norway, aged 20-70 years, was invited to participate in a survey in 1965-1971 (participation rate 83\%).

By December 31, 2005, 4387 (64\%) participants had died and 1163 (27\% of the deceased) had been given an autopsy. Causes of death were tuberculosis (E02, 0.2\%), lung malignancy (E15, 3.5\%), influenza (E38, 0.2\%), pneumonia (E39, 6.5\%) and chronic lower respiratory diseases (E40, 3.2\%). Male sex, early deaths in the surveillance period and E15 were positive predictors of an autopsy examination, whereas old age and E39 were strong negative predictors. Among those referred for a post mortem examination, the cause of death was verified as tuberculosis in $0.3 \%$, lung cancer in $8.1 \%$, acute pneumonia in $2.0 \%$ and chronic obstructive lung diseases in 4.9\%. Cohen's kappa coefficients (E codes versus autopsy) were 0.91 (95\% CI 0.86-0.96) for E15, 0.37 (95\% CI 0.20-0.54) for E39 and 0.65 (95\% CI 0.54-0.76) for E40.

These findings matter when deaths from respiratory diseases are used as end-points in epidemiological association studies and clinical trials.

@ERSpublications

E codes of mortality and autopsy records agree perfectly for lung cancer but only fairly for pneumonia http://ow.ly/CRkCp 


\section{Introduction}

Statistics of deaths from respiratory diseases were once dominated by infectious diseases but over the last 50 years, there has been a shift towards diseases caused by tobacco smoking [1]. New technologies have improved the accuracy of the diagnosis of respiratory diseases, but post mortem examination is still regarded as the gold standard to determine the cause of death $[2,3]$.

The few published population-based autopsy studies that exist are more than 30 years old [4] and indicates that autopsies are heavily biased according to sex, age, race, marital status, place of death and underlying cause of death. Most studies were performed in selected populations and restricted to a single respiratory disease like asthma [5], pneumonia [6], chronic obstructive pulmonary diseases [7], lung cancer [8], other malignant tumours in the lung [9] and pleural diseases [10].

The European short list of causes of death (E codes) groups the diseases from the World Health Organization's International Classification of Diseases (ICD) into 65 different codes $[11,12]$. Respiratory diseases include neoplastic diseases of the trachea, bronchus and lung (E15), and non-neoplastic diseases of respiratory system (E37), including influenza (E38), pneumonia (E39) and chronic lower respiratory diseases (E40) including asthma (E41). The majority of fatal cases of tuberculosis (E02) are also respiratory diseases. Since 1958, chronic lower respiratory disease has been based on the term chronic nonspecific lung diseases or obstructive lung diseases [13, 14]. Seven E-codes are more convenient for planning healthcare than 150 ICD diagnoses of respiratory disease. The validity of E-codes of respiratory diseases has not been examined in the light of autopsy findings.

The aims of this study were to investigate the accuracy and the exposure-disease relationships of the respiratory diagnoses given in mortality statistics by comparing the specific E codes to autopsy findings. Furthermore, we wanted to identify predictors of post mortem referral in a general population.

\section{Methods}

\section{Study population}

A $10 \%$, random, population-based sample of 6811 adults aged 20-70 years in the city of Bergen, Norway, was invited to participate in the Bergen Clinical Blood Pressure Survey in 1965-1971. The medical history including smoking habits and pack-years, and a standardised clinical examination was recorded for each of the participants. Registration of mortality started on January 1, 1964, and ended on the date of death, date of emigration or on December 31, 2005, whichever occurred first; a death certificate was issued by a physician and sent to Statistics Norway $[15,16]$.

\section{Death certificates and $E$ codes}

The underlying cause of death is the disease (or injury) that initiated the series of events that subsequently lead to death [17]. Employees at Statistics Norway transformed these diagnoses on the death certificate into ICD codes [18]. The relevant ICD codes of respiratory causes of death and E codes from 1964 to 2005 are given in online supplementary table S1. The Data Inspectorate, the Norwegian Directorate of Health and Social Services, and the Regional Committee in Western Norway for Ethics in Medical Research granted permissions for this study.

\section{Autopsy records}

Autopsy findings were recorded using the Systematized Nomenclature of Medicine (SNOMED) codes at the Gades Institute of Pathology, University of Bergen [19]. The autopsy procedure did not change between 1964 and 2005. However, in general, more uncertain clinical diagnoses tended to be referred to autopsy and the pathologists tended to favour the more unusual diagnostic groups [20]. The underlying cause of death with topographical (Ibt) and morphological (Ibm) codes were always decided by a senior pathologist and linked to the data file on the basis of the individual identification number. Table S2 shows the selection of SNOMED codes representing respiratory causes of death.

\section{Statistical analyses}

Estimates of agreements between E codes and autopsy findings were calculated for lung cancer, acute pneumonia and chronic obstructive pulmonary disease (COPD) (i.e. emphysema, chronic bronchitis, bronchiectasis and bronchial asthma) and non-neoplastic respiratory diseases. Sensitivity, positive predictive value, false positives (overdiagnosis) and false negatives (underdiagnosis) were calculated as previously described [16]. The 95\% confidence intervals for the indicators of validity were estimated for binomial distribution. Overall agreement between the mortality statistics and the autopsy results, taking chance value into account, was assessed by Cohen's kappa [21] and using the LANDIS and КосH [22] classification. Univariate and multivariate logistic regression were used to explore potential predictors of an 

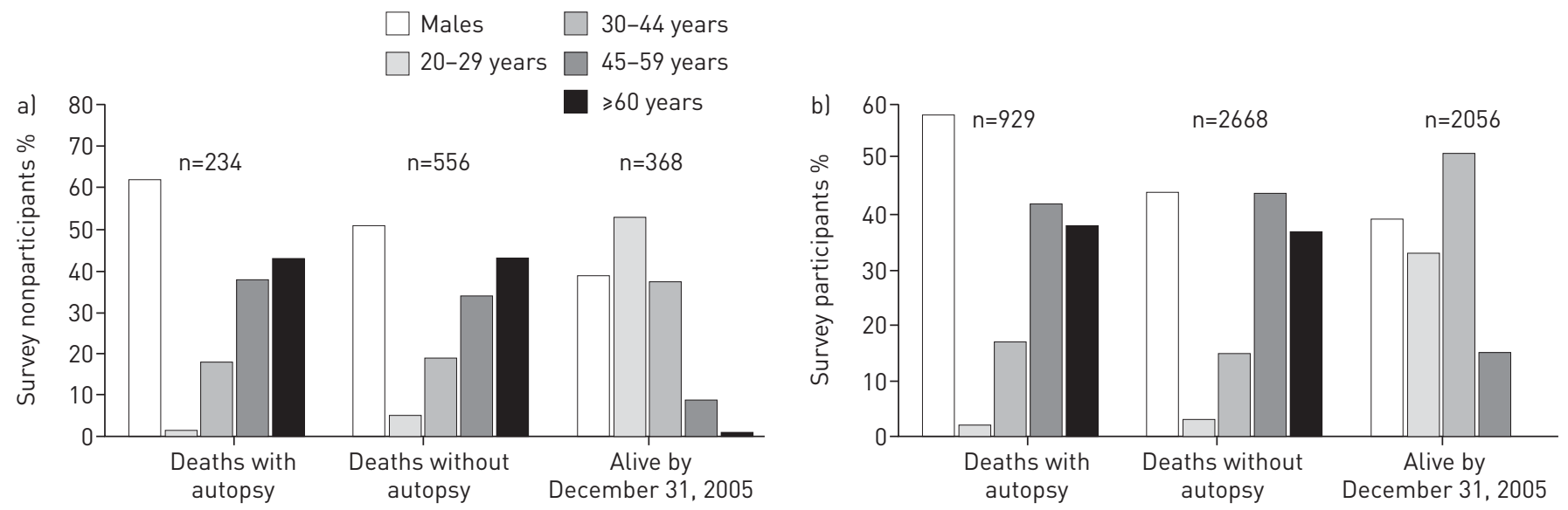

FIGURE 1 Deaths with autopsy, deaths without autopsy and survival to December 31, 2005, in those a) not participating and b) participating in a survey of a general population sample $(n=6811)$ of the city of Bergen, Norway, in 1964, by sex and by age group.

autopsy. Analyses were performed using the statistical software SPSS version 21.0 (SPSS Inc., Chicago, IL, USA).

\section{Results \\ Population sample}

The study population included 3098 men and 3713 women. 5653 (83\%) persons participated in the survey and the participation rate did not differ by sex (fig. 1). The crude participation rate was slightly lower for those aged $<30$ and $\geqslant 60$ years $(79 \%)$ than for the middle aged $(85 \%)$. Among the participants, $58 \%$ were ever-smokers, of whom $27 \%$ smoked $1-9$ cigarettes, $16 \%$ smoked $\geqslant 10$ cigarettes, $4 \%$ were pipe smokers only and $11 \%$ were former smokers. The median (interquartile range) exposure in former smokers was 8.3 (3.0-18.8) pack-years and in smokers was 9.8 (4.6-18.8) pack-years.

During the follow-up period, 4387 (64\%) persons died. The crude death rate was 68 per 100 and 64 per 100 in survey nonparticipants and participants, respectively. The number of deaths per year varied considerably, from 42 persons in 1964 to 147 persons in 1987. A larger proportion of men (69\%) than women (60\%) had died (fig. 1). The age at death varied from 22 to 103 years with a mean \pm SD of $75 \pm 12$ years $(78 \pm 11$ in women and $72 \pm 12$ years in men). At the end of the follow-up period, $65 \%$ of the ever-smokers had died versus $61 \%$ of those who had never smoked. The crude death rates of smokers of $1-9$ cigarettes, $\geqslant 10$ cigarettes and pipes only were $62 \%, 68 \%$ and $81 \%$, respectively.

\section{Sample for autopsy}

Of the deceased, 1163 (27\%) were referred for a post mortem examination (fig. 1) and of these, $23(2 \%)$ had an external examination only. The number of autopsies performed varied per year from a maximum of 53 in 1986 to a minimum of seven in 1999. The autopsy percentage declined from $41 \%$ for 1964-1973 to $10 \%$ for $1996-2005$. More men (32\%) than women (21\%) were referred for autopsy. Age at death was $71 \pm 11$ years. Autopsy results existed for 929 (26\%) out of 3597 survey participants who had died.

\section{Distribution of $E$ codes of respiratory diseases}

In mortality statistics, death due to respiratory diseases was recorded in 618 (14.1\%) cases (sum of E02, E15 and E37). Death due to disease in the circulatory system (E33) was recorded in 2084 (47.5\%) cases. The largest group of respiratory cause of death was E39, with 654 per 10000 deaths, while E40 and E15 each had half the death rate of E39 (table 1). E41 represented only $14 \%$ of all causes with deaths due to E40. E38 and E02 caused few deaths. 16 (3.5\%) cases of death from other nonmalignant diseases of the respiratory system were recorded as E37.

\section{Distribution of topographical-morphological diagnoses of autopsy-verified respiratory deaths}

The underlying cause of death was topographically located in the heart for 391 (34\%) cases, the respiratory system for $190(16 \%)$ cases (including 13 (1\%) cases of fatal lung embolisms), the digestive system for 203 (18\%) cases, the brain/nervous system for 141 (12\%) cases, the peripheral vascular system for $43(4 \%)$ cases and other organs for 195 (17\%) cases. Of the 177 autopsy-verified respiratory deaths, about half had 
TABLE 1 Distribution of European short list (E) codes of respiratory causes in the deceased subjects of $10 \%$ of the population of Bergen, Norway, and in a subsample referred for post mortal examination, initially aged 20-70 years in 1964 and followed until December 31, 2005

\begin{tabular}{|c|c|c|c|}
\hline E code & Disease & $\begin{array}{l}\text { Population sample } n \\
\text { (per } 10000 \text { deaths) }\end{array}$ & $\begin{array}{c}\text { Autopsy subsample } n \\
\text { (\% deaths with this } E \text { code })\end{array}$ \\
\hline E02 & Tuberculosis & $7(16)$ & $4(57)$ \\
\hline E15 & $\begin{array}{l}\text { Malignant neoplasm of trachea, bronchus } \\
\text { or lung }\end{array}$ & $157(357)$ & $89(57)$ \\
\hline E37 & Diseases of the respiratory system & 454 (1035) & 77 (17) \\
\hline E38 & Influenza & $8(18)$ & 0 \\
\hline E39 & Pneumonia & $287(654)$ & $31(11)$ \\
\hline E40 & Chronic lower respiratory diseases & $146(326)$ & $43(30)$ \\
\hline E41 & Asthma & $20(56)$ & $6(30)$ \\
\hline E01-E65 & All deaths & $4386(10000)$ & $1163(27)$ \\
\hline
\end{tabular}

In the autopsy subsample, in $170(14.6 \%)$ cases, of the respiratory diseases E02, E15 and E37 were given as the cause of death. Higher proportions of the autopsies found for E15 and E02 than E39. None of the eight cases was E38 were given an autopsy.

lung cancer and one-third COPD, including emphysema (20\%), chronic bronchitis/bronchiectasis (10\%) and bronchial asthma (1\%). Only $12 \%$ had acute pneumonia (table 2).

\section{Predictors of autopsy}

Autopsy referral was associated with male gender, age below 60 years, early deaths in the surveillance period and E15. E39 was strongly inversely associated with autopsy examination. Participation in the survey and E40 had no significant association with autopsy after multivariate adjustment (table 3).

\section{Agreement between E codes and autopsy findings}

Agreement between E codes and autopsy findings is summarised in figure 2. Further information can be found in the online supplementary text (including table S3) and in the following sections.

\section{E15: malignant neoplasm of the lung}

Cohen's kappa for E15 showed almost perfect agreement between the E coding and autopsy results. The sensitivity and positive predictive value of $\mathrm{E} 15$ were $\geqslant 90 \%$.

TABLE 2 Distribution of fatal respiratory disease ${ }^{\#}$ defined by topographical and morphological pathology (SNOMED) in 1163 persons with autopsy from the population of Bergen, Norway, initially aged 20-70 years in 1964 and followed until December 31, 2005

Pathologically defined disease as cause of death

Persons n (\%)

Lung cancer

Other neoplasms located in respiratory organs

$86(48.6)$

Acute pneumonia

$7(4.0)$

Emphysema

$21(11.9)$

Chronic bronchitis, bronchiectasis

$35(20.0)$

Bronchial asthma

$17(9.6)$

Diffuse lung parenchymal diseases

$1(0.6)$

$6(3.3)$

Pleural empyema

$1(0.6)$

Tuberculosis of the lung

$3(1.7)$

All respiratory diseases

$177(100)$

SNOMED: Systematized Nomenclature of Medicine. \#: there were in addition 13 cases with fatal embolism

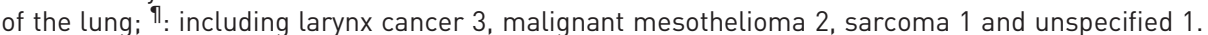


TABLE 3 Multivariate adjusted odds ratios for autopsy versus non-autopsy in 4387 deaths of the Bergen, Norway, cohort initially aged 20-70 years in 1964 and followed until December 31, 2005

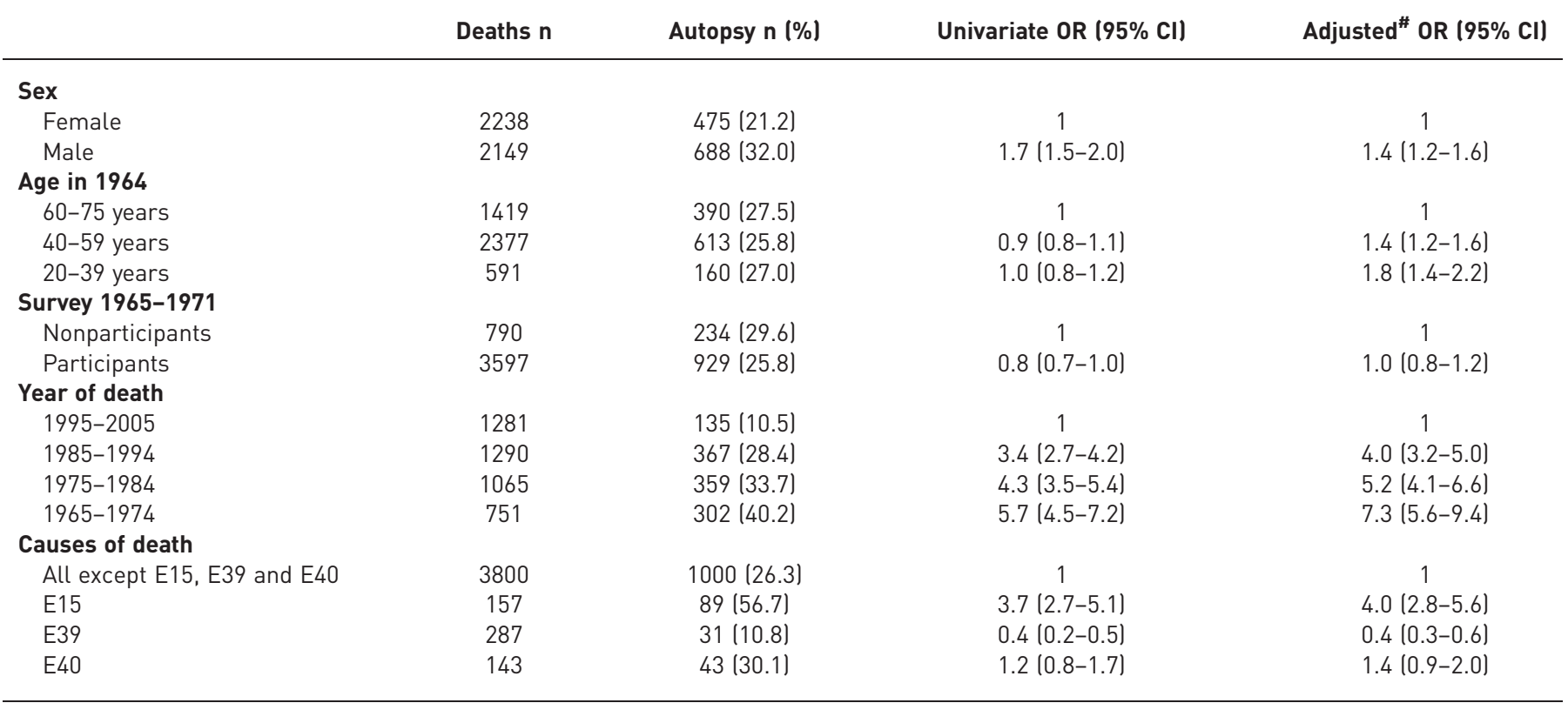

E15: malignant neoplasm of trachea, bronchus or lung; E39: pneumonia; E40: chronic lower respiratory diseases. \#: for all other covariates except for the variable of interest.

\section{E39: pneumonia}

The Cohen's kappa coefficient for E39 of 0.37 reflects only fair agreement between the E code from the mortality statistics and the autopsy results. The sensitivity and positive predictive value for E39 were both poor, and all the validity indicators for this E code had wide confidence intervals.

\section{E40: chronic lower respiratory diseases}

There was substantial agreement between E40 and autopsy-verified emphysema, chronic bronchitis/ bronchiectasis and asthma, with a Cohen's kappa coefficient of 0.65 . The sensitivity and positive predictive value for E40 were higher than for E39 but lower than for E15.

\section{E37: diseases of the respiratory system}

All nonmalignant fatal diseases of the respiratory system in E37 produced substantial agreement, with a kappa coefficient of 0.62 . Sensitivity and positive predictive value for E37 were $63 \%$ and $67 \%$, respectively.

\section{Risks associated with diseases}

The association in the autopsy sample between ever-smokers at survey and deaths due to E15 and E40 had odds ratios (95\% CI) of 9.3 (3.4-25.7) and 3.6 (1.3-10.3), respectively. The association between ever-smoking and autopsy-verified cancer and COPD (emphysema, chronic bronchitis and asthma) as the underlying cause of death had odds ratios of 8.7 (3.1-24.1) and 2.4 (1.0-6.0), respectively.

\section{Discussion}

The validity of mortality statistics using E codes for respiratory diseases varies from perfect agreement for neoplastic disease (E15) to only fair agreement for pneumonia (E39). Disagreement between E codes and autopsy findings was four times more frequent in non-neoplastic respiratory disease (E37) than neoplastic disease (E15). Autopsy referral was biased by age, sex, decade of death and E code. The associations between smoking habits and deaths due to lung cancer or COPD were similar using E codes and autopsy-verified diagnoses.

Mortality statistics are important in the quality assurance of diagnoses and effects of treatment. Coding of the underlying cause of deaths involves 1) the diagnostic process, 2) the completion of death certificate and 3) coding of the death certificates [23]. Each of these steps can reveal errors. Physicians' knowledge of the fatal event, history of the patient's disease and comorbidities vary. 


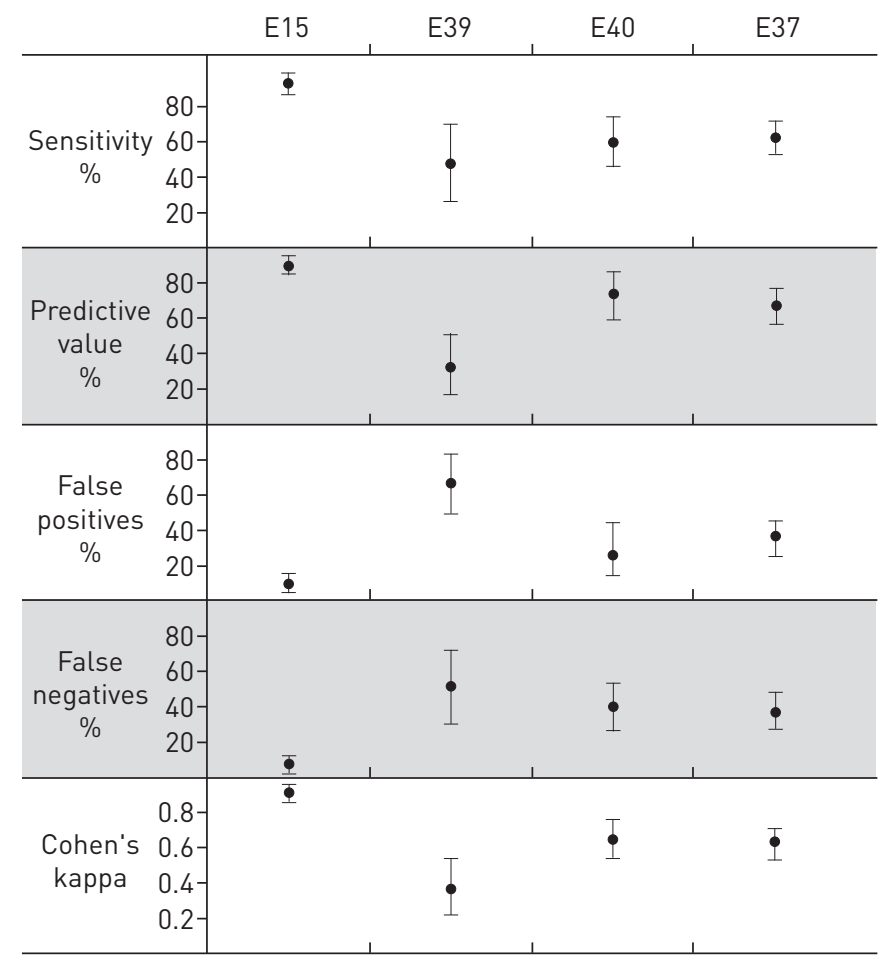

FIGURE 2 Validity indicators of respiratory European short list (E) codes. Estimates and 95\% confidence intervals of sensitivity, predictive value, false positives, false negatives and Cohen's kappa coefficient for $\mathrm{E}$ codes of malignant neoplasm of the trachea, bronchus and lung (E15), pneumonia (E39), chronic lower respiratory diseases (E40), and all nonmalignant diseases of the respiratory system (E37).

The validity (an expression of the degree to which a measurement measures what it purports to measure) of autopsy is dependent on the macroscopic and microscopic criteria of the diseases of the respiratory system. Neoplastic lung diseases may have less ambiguous criteria than acute and chronic inflammatory diseases with destruction and remodelling. The dissemination of the inflammatory and emphysematous changes is not examined morphometrically in a post mortem examination. Respiratory diseases, except for pulmonary neoplasm [24], may have more ambiguous autopsy criteria than cardiovascular diseases or neoplasms in other organs. JøRGENSEN et al. [25] stated that after autopsy and histological examination of asthma deaths in Denmark, many cases were coded by the pathologist as due to emphysema and/or bronchitis. However, E40 groups the chronic inflammatory lower respiratory diseases and may thus improve its validity.

Autopsy has been regarded as the absolute truth for determining the cause of death [26, 27]. The autopsy rates have declined heavily in our university hospital (Haukeland University Hospital, Bergen), as in other pathology departments in Norway and internationally. For the total Norwegian population, only $4.3 \%$ out of 41152 deaths were sent for autopsy in 2005 [28]. Both the pre and post mortem diagnosis and coding can, however, be incorrect. It is well known that clinical observations of the physical signs of chest ailments do vary considerably among respiratory physicians [29]. The interobservation variation in the underlying cause of death measured with Cohen's kappa among pathologists was as high as 0.9 [30]. "Neoplasm" is, for clinicians, a pathologically and anatomically defined disease. Furthermore, the electronic communication between the cancer registry and Statistics Norway is good for malignant cases. This may explain the almost perfect agreement between $\mathrm{E}$ codes of lung cancer and autopsy findings. Quantitative examinations of morphometric measurements of the lung have, so far, not been applied for pathological changes in emphysema, chronic bronchitis or pneumonia in post mortem examinations, while computer tomographic measurement of emphysema and air wall thickness when alive have been used as predictors of mortality [31].

Our distribution of the mortality of E02, E15 and E37 in Bergen between 1964 and 2005 was in crude agreement with the statistics of all E codes of deaths in Norway from 1951 to 2007, being 0.4\%, 2.7\% and $8.9 \%$, respectively [12]. The slight discrepancy for tuberculosis and neoplasm was because the national report included all ages as well as deaths between 1951 and 1963. Our findings were collected from a closed cohort, whereas the official mortality statistics record information on deaths in the entire (open) 
population. The percentage of E40 was 3.2\% in the Bergen population cohort and $3.6 \%$ in the autopsy cohort. In a Danish population cohort from Copenhagen of persons aged $>19$ years followed for almost 25 years, $3.6 \%$ died due to COPD [7]. The percentage of fatal pulmonary embolism (1.1\%) of all deaths in our autopsy sample was identical to that of fatal embolism $(1.2 \%)$ in the national sample of autopsies in Norway in 2005 [28].

Autopsies represent a skewed sample of all deaths. The bodies of women and elderly people were less often sent for autopsy compared with those of men and younger people. An explanation may be that women are older than men when they die and more women die in nursing homes without the opportunity for an autopsy $[32,33]$. This trend of autopsies relative to E codes was also present after taking account of sex, age and decade for autopsy since 1965 (table 3). In an autopsy study of deaths in nursing homes in Oslo, Norway, in 1980-1981 with an average age of 84 years, the majority of deaths were verified as pneumonia [32]. Similar to our study, a study from Minnesota, USA, showed that the proportion of pneumonia cases sent for autopsy was very low [33].

Our sample of 1163 autopsies had approximately the same proportion of deaths defined by E codes and by autopsy, with $7.7 \%$ and $7.4 \%$ for lung cancer, respectively, and $6.6 \%$ and $6.9 \%$ for nonmalignant diseases of the lung, respectively. Errors in death certificates have a tendency to cancel each other out [20], giving false confidence in the overall mortality statistics. In agreement with an autopsy study in nursing homes [32], more cases of pneumonia were diagnosed clinically than by autopsy (31 versus 21 cases) while chronic lower respiratory diseases were more often diagnosed by autopsy (52 versus 43 cases).

Many authors have raised questions regarding the accuracy of the clinical diagnosis in patients dying from cardiovascular diseases [34], malignant neoplasms [35] and pulmonary embolism [36]. Few studies have raised questions about the validity of the mortality figures for respiratory diseases (E37). Our study showed that after autopsy, almost $50 \%$ of the false positives were within the respiratory system. However, for the false negatives, almost half of the cases had an initial $\mathrm{E}$ code diagnosis outside the respiratory and circulatory system. The differential diagnosis between pneumonia and lung oedema can be clinically difficult, especially in the case of elderly patients. In our study, the majority of overdiagnosed cases of pneumonia were other respiratory or cardiovascular diseases. There are few studies on the validity of combinations of symptoms, clinical signs including fever, white cell count and infiltrates on chest X-ray, for the autopsy-verified diagnosis of pneumonia in elderly [37]. In the future, the validity of a diagnosis of fatal pneumonia needs to be improved.

E40 includes ICD J40-J47 or previous equivalent ICD codes for bronchitis, emphysema, other chronic pulmonary diseases, asthma and bronchiectasis. There are no accepted definitions when deaths are caused by or related to COPD. In large, multicentre, controlled clinical trials, specific causes of deaths have been used as additional outcome variables $[38,39]$. In such a selected sample, complete agreement between site investigators and the mortality adjudication committee of the specific cause of death was observed in only $50 \%$ of the cases. It was particularly difficult to distinguish between pneumonia and COPD exacerbation as the presenting terminal illness. In Denmark, JENSEN et al. [7] found poor predictions of spirometric results for fatal chronic lower respiratory disease. Half of those with COPD as the specific cause of death had been found to have normal lung function at a clinical survey $<25$ years previously. In a recent Norwegian study, the diagnosis of pneumonia and COPD on the death certificate was confirmed by autopsy in only $20 \%$ of subjects [28].

One strength of our study is that it included all deaths and all autopsies in a defined urban population over 40 years. This enables us to generalise our findings to the whole population, taking the bias of the autopsy selections into account. It is a real-life study from the daily routines of Statistics Norway and a large, regional department of pathology. A second strength is seen in the comparisons of the validity of mortality statistics of all E codes due to respiratory diseases. Lung cancer has a high validity and pneumonia has a very low validity. The poor validity of mortality from pneumonia reduces its applicability for epidemiological studies on the associations between environmental factors and fatal pneumonia. However, the associations between smoking and deaths from of lung cancer and COPD did not differ overtly from the results of autopsy or mortality statistics.

The weakness of our study is that only hospital deaths were included in the autopsy sample. The sample size of the population, with almost 7000 persons and four decades of follow-up, was too small to acquire precise knowledge on the validity of E02, E38 and E41. Most of the E41 cases had an autopsy diagnosis of emphysema and chronic bronchitis, while half of the E02 cases had another diagnosis of the respiratory system. Furthermore, one-third of the cohort was still alive at the end of the follow-up. This study did not include valid knowledge on respiratory deaths in nursing homes, which have a large proportion of deaths due to pneumonia and stroke [32]. Previously, deaths due to ICD classifications of stroke and ischaemic 
heart disease were examined by autopsy in this community 13, and this showed a better validity for diagnoses of ischaemic heart disease than for stroke.

To improve the mortality statistics, the cause of death should be given electronically by experienced physicians rather than by physicians still in training. Furthermore, the autopsy results should be available within a week after death and their findings should be routinely incorporated into the death certificate.

\section{Conclusion}

Comparing mortality statistics with autopsy shows almost perfect agreement for E15, substantial agreement for E40 but only fair agreement for E39. An autopsy referral is biased by sex, age and the underlying cause of death. Improving the diagnosis of fatal pneumonia in the elderly should be a priority.

\section{References}

1 Gibson GJ, Loddenkemper R, Sibille Y, et al., eds. The European Lung White Book: Respiratory health and disease in Europe. Sheffield, European Respiratory Society, 2013.

2 Kircher T, Nelson J, Burdo MPH. The autopsy as a measure of accuracy of the death certificate. N Engl J Med 1985; 313: 1263-1269.

3 Roulson J, Benbow EW, Hasleton PS. Discrepancies between clinical and autopsy diagnosis and the value of post mortem histology: a meta-analysis and review. Histopathology 2005; 47: 551-559.

4 Kircher T, Nelson J, Burdo H. Descriptive epidemiology of the autopsy in Connecticut, 1979-1980. Arch Pathol Lab Med 1985; 109: 904-909.

5 Silverstein MD, Reed CE, O'Connell EJ, et al. Long-term survival of a cohort of community residents with asthma. N Engl J Med 1994; 331: 1537-1541.

6 Jokinen C, Heiskanen L, Juvonen $\mathrm{H}$, et al. Incidence of community acquired pneumonia in four municipalities in eastern Finland. Am J Epidemiol 1993; 137: 977-988.

7 Jensen HH, Godtfredsen NS, Lange P, et al. Potential misclassification of causes of death from COPD. Eur Respir J 2006; 26: 781-785.

8 MacFarlane MJ, Feinstein AR, Wells CK. Clinical features of lung cancers discovered as a postmortem "surprise". Chest 1988; 90: 520-523.

9 Ducic S. Accuracy in reporting the cause of death. A series with diagnosis at autopsy in a series of mesothelioma and other malignant tumours of the lung. Cand J Public health 1971; 62: 395-402.

10 Svenes KB, Borgersen A, Haaversen O, et al. Parietal pleural plaques: a comparison between autopsy and X-ray findings. Eur I Respir Dis 1986; 69: 10-15.

11 Eurostat. Health Statistics: Atlas on Mortality in the European Union http://epp.eurostat.ec.europa.eu/cache/ ITY_OFFPUB/KS-08-02-022/EN/KS-08-02-022-EN.PDF Date last updated: 2002.

12 Vollseth SE, Tell GS, Thelle DS, et al. Dødelighet og dødsårsker i Norge gjennom 60 år 1951-2010 [Deaths and causes of deaths in Norway during 60 years 1951-2010]. Oslo, Folkehelseinstituttet, 2012.

13 Fletcher CM. Terminology, definitions and classifications of chronic pulmonary emphysema and related conditions. Thorax 1959; 14: 286-299.

14 Fletcher C, Peto R, Tinker C, et al. The natural history of chronic bronchitis and emphysema. An eight-year study of early chronic obstructive lung disease in working men in London. Oxford, Oxford University Press, 1976.

15 Gulsvik A, Humerfelt S, Bakke PS, et al. Norwegian population surveys on respiratory health in adults: objectives, design, methods, quality controls and response rates. Clin Respir J 2008; 2: 10-25.

16 Gulsvik AK, Gulsvik A, Svendsen E, et al. Diagnostic validity of fatal strokes and coronary deaths in mortality statistics: an autopsy study. Eur J Epidemiol 2011; 26: 221-228.

17 World Health Organization. Mortality. www.who.int/topics/mortality/en/

18 Statistics Norway. Dokumentasjon av Dødsårsaker 2005 [Documentation of causes of death 2005]. www.ssb.no/ helse/statistikker/dodsarsak/tilleggsinformasjon/dokumentasjon-av-dodsarsaker-2005 Date last accessed: February 2, 2014. Date last updated: January 1, 2008.

19 Competence Centerfor IT in the Health and Social Sector AS. Koderegister for SNOMED 1. 4 [Code list for SNOMED 1.4]. www.kith.no/upload/1905/snomed_koderegister_msdos_v14.txt Date last updated: May 4, 2002.

20 Hartveit F. Clinical and post-mortem assessment of the cause of death. J Pathol 1977; 123: 193-210.

21 Cohen J. A coefficient of agreement for nominal scales. Educ Psychol Meas 1960; 20: 37-46.

22 Landis JR, Koch GG. The measurement of observer agreement for categorical data. Biometrics 1977; 33: 159-174.

23 Mackenbach JP, van Duyne WMJ, Kelson MC. Certification and coding of two underlying causes of death in the Netherlands and other countries of the European Community. J Epidemiol Community Health 1987; 41: 156-160.

24 Strauss GM, Gleason RE, Sugarbaker DJ. Screening for lung cancer. Another look, a different view. Chest 1997; 111: 754-768.

25 Jørgensen IM Bülow S, Jensen VB, et al. Asthma mortality in Danish children and young adults, 1973-1994: epidemiology and validity of death certificates. Eur Respir J 2000; 15: 844-848.

26 McPhee SJ, Bottles K. Autopsy: moribund art or vital science? Am J Med 1985; 78: 107-113.

27 Anderson RE, Fox RC, Hill RB. Medical uncertainty and the autopsy. Occult benefits for students. Human Pathol 1990; 2: 128-135.

28 Alfsen GC, Mæhlen J. Obduksionens betydning for registrering av dødsårsak [The value of autopsies for determining the cause of death]. Tidsskr Nor Legeforen 2012; 132: 147-151.

29 Gulsvik A, Vale JR. Observatørbetinget malefeil ved fysikalsk lungeundersøkelse [Observer variation in physical examination of the chest]. Tidsskr Nor Laegeforen 1978; 98: 732-734.

30 Veress B, Gadaleanu V, Nennesmo I, et al. The reliability of autopsy diagnostics; inter-observer variation between pathologists, a preliminary report. Qual Assur Health Care 1993; 5: 333-337.

31 Johannessen A, Skorge TD, Bottai M, et al. Mortality by level of emphysema and airway wall thickness. Am J Respir Crit Care Med 2013; 187: 602-608. 
32 Løken AC, Hjort PF, Anker-Nilssen J, et al. Obduksjon av 100 alders- og sykehjempasienter i Oslo 1) Hvor riktige er de kliniske diagnosene? 2) Hva dør egentlig gamle mennesker av? [Autopsy of 100 patients from nursing and old age homes in Oslo. 1) How correct are the clinical diagnoses? 2) What are the causes of death in aged patients?]. Tidskr Nor Legeforen 1984; 104: 1197-1203.

33 Nemetz PN, Ballard DJ, Beard CM, et al. An anatomy of the autopsy, Olmsted County, 1935 through 1985. Mayo Clin Proc 1989; 64: 1055-1064.

34 Hasuo Y, Ueda K, Kiyohara Y, et al. Accuracy of diagnosis on death certificates for underlying causes of death in a long-term autopsy based population in Hisayama, Japan; with special reference to cardiovascular disease. J Clin Epidemiol 1989; 42: 577-584.

35 Engel LW, Strauchen JA, Chiazze L, et al. Accuracy of death certification in an autopsied population with specific attention to malignant neoplasms and vascular disease. Am J Epidemiol 1980; 111: 99-112.

36 Karwinski B, Svendsen E. Comparison of clinical and post-mortem diagnosis of pulmonary embolism. J Clin Pathol 1989; 42: 135-139.

37 Powers JH. Recommendations for improving the design, conduct, and analysis of clinical trials in hospital-acquired pneumonia and ventilator-associated pneumonia. Clin Infect Dis 2010; 51: Suppl. 1: S18-S28.

38 McGarvey LP, John M, Anderson JA, et al. Ascertainment of cause-specific mortality in COPD: operations of the TORCH clinical endpoint committee. Thorax 2007; 62: 411-415.

39 McGarvey LP, Magder S, Burkhart D, et al. Cause-specific mortality adjudication in the UPLIFT COPD trial: findings and recommendations. Respir Med 2012; 106: 515-521. 